\title{
Análise da correspondencia entre Maruja Mallo e Alfonso Reyes (1938-1945)*
}

\author{
Analysis of the collected letters between Maruja Mallo and Alfonso Reyes \\ (1938-1945)
}

\author{
Ma Antonia Pérez Rodríguez \\ Universidade da Coruña \\ Departamento de Humanidades \\ antonia.perezr@udc.es \\ [recibido 30/04/2013, aceptado 04/06/2013]
}

\section{RESUMO}

Análise da correspondencia entre Maruja Mallo e Alfonso Reyes (1938-1945), contextualizándoa co marco espaciotemporal no cal se escribieu e co sistema relacional e profisional da pintora e do escritor; comparándoa cos epistolarios que mantiveron con outros intelectuais, e considerando as aportacións das súas epístolas para coñecer o desenvolvemento da súa obra e a actividade politicocultural dos exiliados. Tamén se analiza o apoio de ambos á II República española.

PAlabras Chave: Editorial Losada e Sudamericana, exilio, pintura, teatro, loita político-cultural, Arxentina, México, Gabriela Mistral, Gómez de la Serna, “Grupo Sur”, Neruda, Ortega y Gasset, Margarita Xirgu, María Zambrano.

PÉrez Rodríguez, Ma A. (2013): “Análise da correspondencia entre Maruja Mallo e Alfonso Reyes (1938-1945)”, Madrygal (Madr), 16: 73-86.

\section{RESUMEN}

Análisis del epistolario entre Maruja Mallo y Alfonso Reyes (1938-1945), contextaluzándolo con el marco espaciotemporal en que fue escrito y con el sistema relacional y profesional de la pintora y del escritor; comparándolo con la correspondencia que mantuvieron con otros intelectuales, y considerando la aportación de sus cartas para conocer la evolución de su obra y la actividad politicocultural de los exiliados. También se analiza el apoyo de ambos a la II República española.

PALABRAS ClaVe: Editorial Losada y Sudamericana, exilio, pintura, teatro, lucha político-cultural, Argentina, México, Gabriela Mistral, Gómez de la Serna, “Grupo Sur”, Neruda, Ortega y Gasset, Margarita Xirgu, María Zambrano.

PÉRez RodríGuez, Ma A. (2013): “Análisis de la correspondencia entre Maruja Mallo y Alfonso Reyes (1938-1945)”, Madrygal (Madr.), 16: 73-86.

\section{ABSTRACT}

Analysis of the collected letters between Maruja Mallo and Alfonso Reyes (1938-1945), contextualizing them within the space-time framework in which they were written and within the relational and professional system between the painter (Maruja Mallo) and the writer (Alfonso Reyes). In this paper, these documents are compared with the correspondence they held with other intellectuals, and it takes into account how these letters contribute to get to know the evolution of their work, and the political and cultural activity of the people in exile. It is also analyzed the support of both to the Second Spanish Republic.

KEY WORDS: Editorial Losada and Sudamericana, exile, painting, drama, political-cultural struggle, Argentina, Mexico, Gabriela Mistral, Gómez de la Serna, “Grupo Sur”, Neruda, Ortega y Gasset, Margarita Xirgu, María Zambrano.

PÉrez RodríGuez, Ma A. (2013): “Analysis of the collected letters between Maruja Mallo and Alfonso Reyes (1938-1945)”, Madrygal (Madr.), 16: 73-86.

SUMARIO: Fuxida, rede de acollida e recepción de Maruja Mallo en Bos Aires. Casuística da integración da pintora no seu novo e oligárquico círculo social. Colaboración de Alfonso Reyes cos republicanos españois. Posta en escea de Cantata en la Tumba de Federico Garcia Lorca. Maruja Mallo e Reyes ante o nacemento das grandes editoriais arxentinas. As epístolas como fonte de información sobre a producción da artista e o escritor entre 1937-1945. Conclusións.

* Madrygal publicará no seu vindeiro número 17 (2014) a edición anotada do epistolario entre Maruja Mallo e Alfonso Reyes. 
O epistolario entre Maruja Mallo (Viveiro, Lugo 1902 - Madrid 1991) e Alfonso Reyes (Monterrey, Nuevo León 1889 - México DF 1959), que se custodia na "Capilla Alfonsina" 1 , a casa-museo do escritor, componse de 23 cartas datadas entre o 20 febreiro de 1938 e o 25 de agosto de 1945.

Non nos consta se se coñeceron en Madrid: a pintora trasladouse coa súa familia a esa capital en 1922 e o ensaista permaneceu alí entre 1914 e 1924. Coincidiron dous anos movéndose en circuítos artísticos-literarios distintos, ela cos seus compañeros da Escola de Belas Artes e el cos dos Instituto de Estudios Históricos e con membros do corpo diplomático, pois de 1922 a 1924 asume unha das consellerías na embaixada de México. Un nexo puido ser Moreno Villa por tratar a Ortega y Gasset e a Gómez de la Serna, pero ignoramos se a artista xa se relacionaba con eles, e tampouco esquecemos que expón na Revista de Occidente en maio de 1928, nin que Ramón escribe encol da súa obra por primeira vez en $\mathrm{El} \mathrm{Sol}$ en xaneiro de 1929. Alfonso Reyes no seu diario únicamente a cita o 5/5/1932 coa frase: "Programas de Le Cinema Comique de Maruja Mallo" (Ruedas 2011: 75), ao enumerar os catálogos, tarxetas, invitacións, etc. que recibe desde distintas terras. E non puido mercar esa carpeta de litografías inspirada nos cómicos do cine mudo, xa que a galería Jeanne Bucher de París nunca a sacou á luz.

A sublevación fascista sorprendeu a Maruja Mallo en Galiza coa súa parella de entón Alberto Fernández (Mezquita). Os seus familiares de Vigo escondérona e na súa mente quedou gravada a represalia franquista nesa cidade, nas vilas da súa ría e en Galiza enteira, como se desprende do seu artigo na Vanguardia (Maruja Mallo 1938), un texto con moitas concomitancias cos publicados por Luis Seoane (1938) no xornal Crítica de Bos Aires e en La Galice sous la boute de Franco ${ }^{2}$, e que, como estes, se inscribe nunha das liñas da propaganda seguida en 1937 pola embaixada da II República en Arxentina. A barbarie falanxista deixoulle unha sinal indelébel como a todos os exiliados; por iso se comprende que en 1941 lle conte a Alfonso Reyes que ese recordo e a invasión de Francia lle desencadearan unha depresión. Xa padecera outra en 1929-1931 ocasionada por rachar o seu noivado con Alberti, o seu grave accidente de coche con Mauricio Roësset e o inmediato suicidio deste. Segundo os exiliados galegos, a partir de 1952-1953 arrastrou ata os sesenta outra forte depresión cuxo inicio coincidiu co agravamento da enfermidade de Constancio Vigil e que se acrecentou co falecemento deste e o desencanto que lle xeraron os últimos anos do peronismo.

En xaneiro de 1937, Maruja Mallo cruzou por Tui a raia lusa. Dispoñía dun convite da "Sociedad de Amigos del Arte de Buenos Aires", que, seguramente, logrou grazas a Tota Atucha (Molins 2012: 87), por matrimonio condesa de Cuevas de Vera, unha millonaria arxentina do grupo das "condesas de Ortega", amiga de Alberti e Buñuel e a quen trataba Reyes. Atravesa Portugal sen problemas e o 24/1/1937 Gabriela Mistral, que a acollera en Lisboa, redacta dúas cartas para recomendala: a Victoria Ocampo di1le: "allá les 1lega Maruja Mallo. Ojalá pudiesen ir por el mismo barco los demás profesores que habría que poner a salvo, en bien del día de mañana de su país. Yo sé que usted le confortará el alma acongojada bajo su sonrisa que ella lleva" (Horan / Meyer 2007: 253); e a Alfonso Reyes: "les lleva estas palabras Maruja Mallo y se lleva a ella misma como mejor presentación. Usted le dará la alegría que necesita para poder trabajar sin demasiada pena lejos de su tierra. Ella le contará un trabajo muy lindo hecho por Cosío con México en bien de gente española" (Vargas Saavedra 1991: 107). El respóndelle o 18/2/1937: "Desde luego ofrecí a Maruja Mallo todo lo que de mi se le ofrezca" (ibid. 110), aínda que non a informa de que o 7/2/1973 recibiu "larga vista de tarde de Faustino Jorge, para hablarme de la llegada de Maruja Mallo el 9, en el Alcántara, contratada por Amigos del Arte; a ver si la embajada española evita incidentes con la policía a su desembarco" (Enríquez Perea 2012: 84).

\footnotetext{
${ }^{1}$ O meu máis sinceiro agradecemento á Doutora Da Alicia Reyes, directora da "Capilla Alfonsina” en México DF., pola súa atención e facilidades. Tamén a todo o competente, eficiente e afábel persoal de dita entidade.
} 
Á amizade que cedo trabaron, coidamos que contribuíu a proximidade de ambos con respecto a Ortega y Gasset; este e Reyes mantiveron un trato salpicado de desencontros que fai augas en 1948-1949 por varias declaracións extemporáneas do pensador madrileño. Porén, nunha carta a Maruja do 1/7/1941, rógalle que lle transmita o seu recoñecemento, e faino, despois de que ela lle contase que estaba só; algo que probablemente non o colleu de novo, segundo se deduce da redacción de Reyes.

A artista non lle agachou que esa soidade lla ocasionou manter que a idiosincrasia do home arxentino a facía pertencer a unha sociedade formada por un grupo disxunto de comunidades de inmigrantes, por "un conglomerado humano"; pero si que ao anterior Ortega lle engadiu a preocupación desmesurada pola súa imaxe social. Doutra parte, ocultoulle a vinculación do filósofo cun sector de Acción Católica profranquista e impulsor de revistas filofascistas (Baluarte, Nueva Política, Sol y Luna, etc.), os problemas que tiña ao non cobrar de Espasa-Calpe o soldo como asesor e os dereitos de autor, o feito de que non se entendera coa editorial Sur (nin coas novas), e que as súas narcisistas actuacións públicas suscitaran a condena dos seus seguidores.

Gabriela Mistral debía saber a boa conexión que xurdiu entre Maruja e Reyes, xa que en maio de 1937 acode a el para que a poña ao tanto das adversidades de Alberto Fernández (Mezquita): “...le ruego decir a Maruja Mallo que su recomendado ha tenido penas, y serias. Que le encargue a sus amigos de Galicia a fin de que no salga mal de su penuria" (Vargas Saavedra 1991: 111). De novo, apela a el noutra misiva de agosto para que lle notifique que "...ya pasó Fernández lo peor; parece que sigue preso pero no lo mandan a la frontera. Eso me dice mi Cónsul en Porto que ha hecho lo que pudo, y yo hice por él mas de lo debido, y él ha sido poco digno de esa gestión y de las de otras de buenas personas portuguesas, todas ellas presas por su culpa" (Vargas Saavedra 1991: 112). O 23/9/37 contéstalle Reyes: "he dado a Maruja Mallo sus recados, que ella mucho agradece" (Vargas Saavedra 1991: 113).
A amizade entre a pintora e a premio Nobel forxouse entre 1933 e 1935, cando esta se encargou do consulado do seu país en Madrid. De acordo co que Maruja lle indica a Reyes, tamén lle estaba agradecida polo comportamento que tivo con ela durante a súa estadía de 1938 en Arxentina. Logo o seu contacto interrómpese (Maruja retómao puntualmente en 1943 e 1945) xa que en 1939 só lle comunica a Reyes que Victoria Ocampo se atopa en París, pero non que se reuniu coa poetisa en Cannes, nin que lle axudara a montar o consulado de Chile en Niza (Horan / Meyer 2007: 35, 101). Alén disto, non a chega a ver cando expuxo en Nova York, circunstancia que lamenta nunha carta do mesmo ano desa mostra e noutra do 10/10/1954:

En octubre de 1948 cuando se realizó mi exposición en Nueva York, encontré tu firma en el libro de dicha exposición. Te busqué por el consulado de Chile que no sabían por donde andabas. Ahora te escribo, aunque creo que sabrás hemos tenido la desgracia de perder a D. Constancio Vigil, que fue para mi un encuentro providencial, como cuando te encontré a ti, arcangélica Gabriela después de atravesar la frontera Portugal. Tu mensaje fue ponernos en contacto, en un mismo punto de la tierra donde vivíamos en ese momento los tres. Tu detrás de la embajada de España donde vivías y yo en esa embajada frente a donde vivía él. Creo que hasta los nombres son simbólicos. Nada hay al azar, esto me dijiste en Portugal. El mundo es matemático.

Creemos, Gabriela, que nadie mejor que tu $-\mathrm{y}$ por lo mucho que él te quería a ti- puede hacer un artículo a su memoria para "Atlántida" y soy yo quien debe pedírtelo ${ }^{2}$.

Por outro lado, parece compracer á pintora que as conferencias pronunciadas por Gabriela Mistral en Bos Aires en 1938 ensombreceran as teatralizadas nas que Gómez de la Serna utilizaba obxetos estrambóticos, ou por inesperados sorprendentes, que aparatosamente extraía dunha xigantesca maleta. Lembremos que dous meses antes de que informase a Reyes do éxito da poetisa, Ramón (a quen alcuma "Anaconda”) negara a súa sinatura para unha proclama

\footnotetext{
2 Ambas as dúas cartas consérvanse na Biblioteca Nacional de Chile, Sala Gabriela Mistral. Esta, do 10/10/1954, co nº 000921017, identificador AE0002226 (1030/1).
} 
impulsada desde a embaixada de España (da man de Amado Alonso), contra os bombardeos franquistas sobre Madrid (Huici 1978: 30).

Ao pouco de arribar, Maruja comeza co novelista Constancio Vigil unha prolongada unión sentimental con curtas e moi peculiares pseudo-intermitencias. Xa están xuntos o 20 de febreiro de 1937 cando "...el concejal Camolli, Xavier Bóveda, Blanco Amor Eduardo, Blasco Garzón, toda la embajada y el consulado, Caballero, Gomez Ver, Maruja Mallo la pintora, Constancio Vigil..." (Montoya de Burundarena 1963: 9) despediron a bordo do "Southern Cross" a Díez-Canedo, ata dez días antes embaixador da II República. El era propietario do potente grupo Atlántida, que publicaba revistas para nenos, para os mozos, ou para a muller, da editorial dese nome e dunha distribuidora; nelas desempeñaron diversas tarefas Carmen Muñoz, Rafael Dieste, Otero Espasandín, Luís Seoane, Castelao, quen nunca esqueceron a intercesión de Maruja para que isto ocorrese. Nas súas cartas a Reyes nótase a gran vinculación da pintora con Atlántida. Ela foi quen xestionou que el colaborase nesa revista (Perea 2012: 153), daquela dirixida polo prestixioso Ortiga Ankermann, orientada a receptores de alta cultura, con coidadas fotografías e ilustracións (Federico Ribas era o director gráfico do grupo editorial) e espazos destinados á vida mundana, á creación e ao humor.

Alfonso Reyes desempeñou por segunda vez como embaixador en Arxentina desde o 22 de xullo de 1936, e, legalmente, ata 1941. Para o seu nomeamento foi decisivo que o ministro de Asuntos Exteriores Genaro Estrada confiase nel para defender a aposta azteca na Conferencia Interamericana de Consolidación de la Paz de Bos Aires (1936), á que asistiu o presidente Roosevelt e Cordell Hull. Nela o anglófilo Carlos Saavedra Lamas, ministro de Relacións Exteriores de Arxentina e premio Nobel da Paz, aviese aos plans de EEUU para Latinoamérica, unha postura acorde co seu acatamento da política de "non intervención" con respecto á guerra civil española. Maruja refírese a el xocosamente nunha das cartas, pero os informes oficiais de Reyes deixan ver a súa desconfianza cara a Saavedra por xulgalo personalista e arrogante (Zuleta 1996: 888).
O 1 de xaneiro de 1938 o intelectual rexiomontano retorna a México. Maruja, na primeira carta que lle remite, fálalle da maior das súas despedidas, de Prensa Hispánica e da exposición montada no edifico modernista de Crítica. Esta mostra era de libros e de case mil fotografías e recortes de prensa sobre a vida en Madrid desde xullo de 1936. Conquiriu unha enorme repercusión pola publicidade dese difundidísimo xornal, moito máis apegado ao modelo Hearst que ao Pulitzer e á do resto dos medios propiedade do seu controvertido, omnipresente e todopoderoso director, Natalio Botana: unha radio, un noticieiro cinematográfico, unha produtora e unha distribuidora de cine.

Tamén se refire á posta en escena de Cantata en la Tumba de Federico García Lorca, de Alfonso Reyes, un lírico canto funerario encadrábel na praxe condenatoria que espertou en Hispanoamerica o fusilamento do poeta, en especial en Bolivia, Ecuador, Guatemala, El Salvador e, sobre todo, en Chile e Arxentina. Con anterioridade, xunto a poemas doutros autores españois, galegos e americanos, xa o recitara Mony Hermelo en xuño de 1937, noutra homenaxe a García Lorca recollida nun libro dese ano deseñado por Luís Seoane (Frontini 1934). A compañía de Margarita Xirgu escenificouna o 23 de decembro con música de Jaume Pahissa.

Xirgu asinou en novembro de 1937 un documento de adhesión de intelectuais cataláns e españois ao goberno republicano, manifestando abertamente o seu compromiso coa "España leal". Isto induciu os profranquistas a intensificar a forte campaña que desenvolvían desde antes na súa contra e que trataron de contrapesar Crítica, Noticias Gráficas, La Vanguardia, Última Hora, Galicia da Federación de Sociedades Gallegas, El Diario e España Republicana. O escritor de Nuevo León contribuíu a mitigala así, xa o cinco de maio participou con ela, E. Guibourg (xornalista de Crítica) e Jiménez de Asúa (encargado da embaixada de España) nunha reportaxe (Rodrigo 1988: 344) sobre Lorca emitida por Radio Rivadavia desde o camerín da actriz no teatro Odeón, unha hora antes da estrea de "Doña Rosita la soltera". Sete meses máis tarde, Reyes rexistra no su Diario (Enríquez Perea 2012: 213):

Buenos Aires, 24 diciembre 1937: anoche, en el Smart, Margarita Xirgu, después de Bodas 
de Sangre de Federico García Lorca, se puso mi "cantata" con la música de Pahissa (Jaime). El teatro, henchido hasta reventar y tomado todo desde ocho días antes, se vino abajo en verdaderas tempestades de clamores. Me hicieron hablar desde mi palco, a tanto gritar el nombre de México y el mío...

En Cantata en la Tumba de Federico García Lorca, os versos adquiren categoría de ololygé. É unha elexía na que Xirgu interpretou a nai que chora e reproba a morte do seu fillo con queixumes hímnicos a modo de threno, Alberto Contreras o pai que tenta reprimir o seu sufrimento, Isabel Pradas a aflixida irmá e Amelia de la Torre a noiva, que reclama para o seu amor asasinado as flores, os frutos e os ulidos de América, mentres o coro patentiza o drama da guerra ao erguer a súa voz loitadora e doente cal a do pobo masacrado. Reyes, especialista en cultura clásica, asígnalle un rol parangonábel ao que desempeñaba nas traxedias gregas facendo converxer nel a función épica, avisadora e premonitoria. $\mathrm{O}$ poema trasloce que un dos axiomas do americanismo xa penetrara no imaxinario dun escritor tan europeizado coma el, pois na Cantata semella que desexa transmitir que o futuro está no Novo Continente. É unha idea que a partir de 1941 defenderán desde México os exiliados Juan Larrea, Eugenio Imaz e, tanxencialmente, León Felipe, cunha visión impregnada de misticismo e afastada da visión máis realista e crítica que Reyes expresou nos seus ensaios.

Cantata en la Tumba de Federico García Lorca repúxose o 27 de decembro e ao longo desa semana a prensa bonaerense afín á II República destacou a súa calidade literaria e interpretativa, a boa adaptación entre o texto e a partitura de Jaume Pahissa e a empatía desatada co público pola música das guitarras. Pero non comenta nada sobre a achega da pintora que, nunha das fotos tiradas ao final da súa primeira posta en escena, sae en segunda fila, mentres vemos na de diante a Pahissa, Xirgu e Reyes. A Cantata representouse a continuación de Bodas de Sangre e o tempo que debeu mediar entre ambas as dúas pezas sería o xusto para levar a cabo as variacións escenográficas necesarias sen alongar demasiado a pausa, o cal condicionaría que os decorados fosen moi sumarios. Isto explicaría que Maruja realizara outros máis complexos para a exposición nos locais de Crítica e, especialmente, para a representación do 2 de agosto de 1938, da que se conserva unha fotografía (o decorado coincide bastante co esbozo que lle mandara a Reyes) e cuxa recadación se destina aos nenos que soportaban a Guerra Civil na Península (Mangini 2012: 218).

De aí o esquemático deseño do final da carta que inicia a correspondencia entre o intelectual de Monterrei e a pintora de Viveiro. Nela adiántalle que posiblemente "se haga una película con la Cantata" e que Prensa Hispánica quere publicala, ao que el lle responde o 1/3/1938: "Espero con el ánsia que usted supondrá la edición de mi Cantata, con los escenarios de usted que, a juzgar por el diseño de su carta, serán magníficos". O devezo non se chegaría a consumar, xa que en xullo de 1938 tomou posesión da legación española Osorio e Gallardo, quen centrou a axencia, dirixida por J. Benegas (dependía da "Oficina de Prensa al Servicio de la República Española"), en efectuar unha propaganda proactiva orientada tanto aos medios como á poboación, en distribuír novas sobre á Guerra Civil a máis de cen xornais latinoamericanos (Díaz-Ragañón 2006: 908) e no programa de radio "Habla Madrid", e en atraer as casas e centros das distintas comunidades de emigrantes. Así mesmo, ficaría frustrado o proxecto de filmación da Cantata en la Tumba de Federico Garcia Lorca; en troques, a produtora Compañía Industrial Filmadora Arxentina financiaría a rodaxe da versión de E. Guibourg de Bodas de Sangre, con Margarita Xirgu no papel estelar. Convén engadir que o contacto de Maruja Mallo con Xirgu debeu de ser pouco despois de marchar Alfonso Reyes, a teor do que a actriz lle comenta en carta do 4/4/1938: "Maruja Mallo sigue en la embajada de España. Hace mucho que no la vemos"

O 26 de decembro de 1937, as asociacións republicanas ofrecéronlle a Reyes unha despedida que presidiu Jiménez de Asúa e o cónsul xeral Blasco Garzón. La Nación, Noticias Gráficas e Crítica, durante os cinco días seguintes (posteriormente Galicia e España Republicana),

\footnotetext{
${ }^{3}$ Carta de Margarita Xirgu a Alfonso Reyes, conservada en México DF na "Capilla Alfonsina”.
} 
recolleron con profusión o acto (Robledo 1998: 197-201). Os tres xornais e Alfonso Reyes (Enríquez Perea 2012: 155-156) concordan en que os asistentes se aproximaban aos 3000, cantidade que tamén achega Zuleta Miranda ${ }^{4}$ (1996: 881). En sucesivas cartas, Maruja pono ao corrente de que puideron ser máis, que notábeis persoeiros telegrafaran a Lázaro Cárdenas para eloxiar o seu facer, que se rumoreaba que o designarían embaixador en Washington, e congrátulase polo labor que desenvolvera en Rio de Janeiro. Estas noticias deberon ter un efecto balsámico para o seu amigo nunha conxuntura de dor e incertidume ao ser apartado do servizo activo a causa da remodelación que emprendeu o goberno mexicano nas legacións no exterior, ao pouco de morrer Genaro Estrada.

A artista descoñece que lle oculta a súa situación profesional e financieira, e el non desfai o erro nin cando ela infire que será unha casa espléndida e o advirte de que garde un panel de parede para un cadro que lle promete enviar. A actitude é diferente con Henríquez Ureña, ao que lle confía o 21/2/1939 que a vivenda será modestísima e que a edificará "hipotecando y con el dinero que se me devolvió de pensiones, al retirarme del servicio exterior. La hice para mis libros y mi trabajo: una biblioteca extensa y cómoda, y un rincón para dormir y comer debajo de una escalera" (Lara 1981: 198). Antes, o 15/8/1938 reférelle a Victoria Ocampo que neses meses se sostiña grazas a cobrar anticipadamente a xubilación e ás colaboracións en prensa, e pídelle traballo en Suramericana, editorial que desde un principio contara cunha forte achega monetaria dela e de Oliverio Girondo, con quen Reyes andara en tratos sobre o seu labor nesa editora (Saïtzeff 2008: 218-232). A ela diríxese desde Rio de Janeiro nestes termos:

Yo necesito un sueldo para vivir. Tengo ofertas de algunas universidades yanquis (...) Pero es un último recurso (...) Quiero antes tentar otra posibilidad: el desarrollo de su Editorial ¿le permitiría ayudarme de un modo estable, dentro de lo humano y lo que a sus intereses convenga?. Yo creo que de aquí regresaré a México, y entonces veríamos donde conviene que me instale. (Perea 1983: 32)

A Maruja non só lle agocha a mala etapa que está a pasar, senón que non lle contesta as súas preguntas sobre Trotsky ou sobre as súas posibilidades de ocupar a vacante da legación mexicana en USA, pese a que desempeñara alí algunha misión, pois en carta ${ }^{5}$ remitida desde Chile por Pablo Neruda e G. Seguel o 8/6/1938 lemos: "Haremos un Congreso de Intelectuales en septiembre (...) No quiero que deseches ligeramente nuestra invitación, sabemos tus ocupaciones en Nueva York, pero este asunto tiene inmensa importancia". As reservas continúan cando a pintora aplaude o seu servizo en Rio de Janeiro, e nada lle aclara sobre o corolario desa operación para acadar acordos comerciais sobre petróleo. Era un obxectivo crebado en tanto que aínda non se definira a empresa pública que logo xestionaría o cru mexicano expropiado, polo longo brazo de EEUU e porque Getulio Vargas viña de nacionalizar o petróleo brasileiro. $\mathrm{Na}$ práctica, pode dicirse que fracasara le savoir faire de quen fora en Rio plenipotenciario nos anos 1930-1933. Para alén disto, o desenvolvemento das negociacións ad hoc orixináranlle frustración, como se desprende da citada misiva do 15/8/38 a Victoria Ocampo:

...me han enviado a la comisión comercial en que ando, reconociéndome mi categoría de embajador para facilitar mis funciones solamente, pero sin nombramiento efectivo, sin los honorarios correspondientes, ni devolverme al servicio activo. Mis trabajos dependen de un departamento comercial y no del ministerio de Relaciones de mi país. Mis modestísimos honorarios, también. Bastan para ir sosteniendo a los mios y pagar aquí mis gastos, que he reducido al mínimo. No creo que dure mucho este trabajo, porque presiento que mi colaboración va llegando a su fin, y porque estas cosas son muy ajenas a mis hábitos y a mi espíritu. Regresaré, pues, a México, en las mismas condiciones que antes, pues ya usted supone que, aunque he manejado cuantiosos intereses, no acepto comisiones de mercanchife ( sic). (Perea 1983: 31-32)

\footnotetext{
${ }^{4}$ Baséase en documentación custodiada no Arquivo Histórico da Secretaría de Relacións Exteriores de México.

${ }^{5}$ Carta conservada na "Capilla Alfonsina" e escrita en papel timbrado da "Alianza Intelectual de Chile para la Defensa de la Cultura".
} 
Os epistolarios entre o ensaísta e $\mathrm{M}^{\mathrm{a}}$ Rosa Oliver ou Ocampo adoitan ser máis extensos, dilatados no tempo e menos convencionais que o que mantén con Maruja Mallo, talvez por partillaren intereses literarios e por prevención ante a mordacidade da pintora. Os que a trataron sinalaban o seu humor corrosivo, "oportuno" e irreverente; a isto xuntouse que na vida cotiá era coherente co xeito de pensar que, segundo Concha Méndez, xa preconizaba a comezos dos anos trinta: "Maruja Mallo, que proponía liberar las reacciones primarias, la espontaneidad, decía que todos esos buenos tratos y buenas costumbres no eran más que mala educación. Decía que el colegio nos condicionaba a ser unos hipócritas" (Ulacia Altolaguirre 1990: 43). E en 1940 continuaba sostendo o mesmo, pois nunha das cartas recoméndalle a Reyes que eduque mal a súa neta.

Coidamos que esa congruencia nin a entenderon nin a transixiron os seus "exquisitos amigos". A respecto deles, a pintora debeu ir dándose conta de que os moitísimos cartos convertían en extravagancias exentas de vulgaridade certos comportamentos nada ortodoxos deles, en tanto non toleraban os seus, a pesar das licencias que supoñía ser artista. Debeu ir decatándose de que ela non respondía ao papel que lle fixaran dentro do conservador grupo no que se movía, no que era unha intrusa sen máis transcendencia da que lle quixesen outorgar. Pode que fose reparando que para os seus compoñentes (con contadas excepcións) a cultura era pouco máis que un inusual lustre, un distintivo que os facía excepcionais entre os seus iguais, e que a utilizaban para dar corpo a un mini-grupo que tentaba ser inconfundíbel dentro da súa clase social; clase que os protexía e na que perduraban os valores herdados da colonización.

Maruja non modificou en Bos Aires o rol de xénero que modelara en Madrid entre 1922 e 1935; nel prevaleceron postulados e pautas afastadas dos estereotipos hexemónicos, e non o variou aínda que non agradase no ámbito socioeconómico no que se introduciu en 1937. Este era un contexto que permitía contravencións aos membros propios, sabendo que traspasaban moi pouco o seu perímetro, que podía mediatizar a súa publicidade fóra del; tamén llas aturaba porque tiña a seguridade de que podía consentir eses quebrantamentos porque non facían perigar os seus privilexios, xa que era consciente do moito que posuían de hedonismo e ludismo. Porén, durante uns sete anos Maruja permaneceu dentro desta esfera relacional, quizais porque iso lle permitía introducirse no nicho social con maior capacidade económica de Arxentina. Esta determinación, motivada xa pola inercia, o temor ao porvir, a vaidade, a conveniencia ou, en definitiva, á mestura de todo, pode que se afianzase despois da súa segunda depresión. Na liña do que lle precisa a Reyes sobre como a conqueriu vencer, é factíbel que saíse dela con maiores recursos para obviar as críticas e neutralizar os sentimentos. Non hai que esquecer que:

Maruja Mallo era una artista y una mujer sin prejuicios, y era lógico que supliera la ausencia de España a su modo, sin excesivas lágrimas ¿Quién puede dudar que la guerra la desquició como a todos los que iniciaron el éxodo, y que su mundo se partió en dos, hasta convertirla en aquella figura errante que con la misma facilidad que hacia amigos nuevos los olvidaba? (De la Fuente 2002: 27)

Ficar nese círculo debe entenderse contemplando a súa condición de muller soa nun país extranxeiro onde os exiliados non gozaban de aprezo. Tendo presente que, de non desbotalo, o seu rol de xénero tamén lle ocasionaría problemas con outros grupos, incluído o dos refuxiados, composto maioritariamente por homes que combatían pola democracia, polo xeral, sen pensar nos dereitos que dentro dela lle corresponden á muller. O desafío da pintora desde unha posición de debilidade ante a mentalidade imperante e a súa querenza polo peronismo están na base do rexeitamento que sufriu por parte das escritoras antes mencionadas e das súas endiñeiradas amizades. E as consecuencias de non traizoar ese rol de xénero, unido á súa recusación do partido comunista (non do troskismo), pode que favorecese a súa inclinación cara ao partido dos descamisados, tan odiado por esa oligarquía e polos desterrados.

$\mathrm{Na}$ correspondencia con Reyes, advírtese que a artista evita falar do xusticialismo, algo comprensíbel, pois sabería da súa repulsa cara a ese movemento, e é claro que o distanciamento coa directora de Sur se remonta a 1940; o de Mª Rosa Oliver (1981: 28-29) é, así mesmo, dos 
inicios desa década. Esta última chegou a sentir estima por Maruja; ben o ilustra que en xullo de 1938 requirise os oficios de Reyes co fin de axudarlle:

Maruja Mallo está muy preocupada pues con la llegada de Ossorio (sic) y Gallardo, a quien no conoce, tendrá que dejar su alojamiento en la embajada y esto le crea una situación económica sin solución. Esto pensé: si a usted le sería posible hablarle a Ossorio y Gallardo (a su paso por Brasil) de Maruja, y decirle, al pasar, lo vinculada que está ella a los grupos intelectuales de Buenos Aires. Quizá entonces a Ossorio se le ocurra dejarla de attachée en la embajada. Todo esto es idea mía; Maruja no sabe nada de este pedido; sabe únicamente que estoy muy preocupada con su situación.

Yo no entiendo de "diplomacia", de modo que no sé si estoy pidiéndole algo imposible. $\mathrm{Si}$ es así, usted me disculpará comprendiendo por que lo hago. (Zaïtzeff 2009: 102)

No caso de que a el lle fose factíbel satisfacer a petición, segundo reza nunha das cartas da pintora, non resultou eficaz, xa que ao chegar Osorio y Gallardo debeu irse da legación española onde residía desde a marcha de Alfonso Reyes a México.

Por outra banda, Maruja é lacónica cando alude a Spruille Braden, a quen coñeceu por medio do ensaísta. Este, con frecuencia, refírese a el no su diario de 1936-1939: entendíanse ben no personal e no político; de feito, Reyes redactara unha memoria sobre as aspiracións de Estados Unidos en América Latina que o norteamericano entregara a Roosevelt (Enríquez Perea 2012: 63). Braden, sendo embaixador en Arxentina, abandeirou "a contra" a Perón e o efectivo slogan electoral de 1946 "Braden o Perón", sintetizou o enfrontamento entre as dúas nacións, un choque do que tirou beneficio o xeneral. Nas cartas a Maruja, o escritor non menciona a este empresario petroleiro, cuxos mandatos como embaixador en varios países suramericanos coincidiran cos períodos nos que neles houbera golpes de Estado. En troques, si se refire a el nunha misiva do $13 / 2 / 38$ a Victoria Ocampo: "Llegué a N. York el 20, donde viví cinco días en casa del embaixador Spruille Braden y traté algunos proyectos de trabajo. De allí, otros cinco días a Washington, donde también dejé ciertos cables tendidos" (Perea 1983: 26).
Sorpréndenos, porque a pintora se relacionara bastante con el cando estivera de delegado de USA na Conferencia para la Paz del Chaco (1936-1938), e aínda máis de comprobarse que son certas as asombrosas e insólitas anotacións de Reyes no seu diario o 20 e 25 de outubro de 1937: "El sábado matrimonio religioso y fiesta Robert Lyons y Maruja Mallo, que de la casa del embajador Braden se fueron a pasar la noche en Los Naranjos, que les prestamos al efecto. Ayer volvieron de noche y embarcaron para Rio a las 10 pm" (Enríquez Perea 2012: 138).

O nacemento da industria do libro en Arxentina asoma estimulante nas epístolas da artista, en nas do escritor desalentador no que atinxe ao seu país. El perfílao lamentábel cando con Cárdenas gozou de axuda oficial e a reforma no ensino propiciou un mercado que atenderon editoras encarreiradas aos adolescentes, aos estudantes de todos os niveis e ao entretemento. Para Reyes é calamitoso transcorrido un bienio de que Cosío recorrese a el o 17/10/1937 para que lle proporcionase enderezos de librerías, prezos, "costumes comerciais", etc. de Arxentina, e de anunciarlle: "Vuelvo a encargarme del Fondo de Cultura Económica (...) Lo he encontrado con muchos mas recursos, pero casi muerto por abandono. Suárez, Villa y yo, queremos darle un impulso enorme. Para eso requerimos la ayuda de todos los amigos y de usted muy particular" (Enríquez Perea 1999: 55). Posiblemente en abril de 1939, acuse a ausencia de editoriais semellantes ao que axiña sería esa editorial fundada por Cosío Villegas en 1934, con orientación á economía, ata que amplía o seu campo coa entrada nela dos republicanos, a maioría integrantes da "Casa de España", un organismo que nesa época lle presta apoio monetario cando o FCE llo solicita (ibid. 77-80).

Cómpre precisar que en 1938, en México, xa funcionaba a interamericana "Ed. Gonzalez Porto" (fundada en Cuba), que contaba con boa calidade, librerías no distrito federal e unha distribuidora, e era propiedade, fora creada e estaba dirixida polo galego dese apelido. A partir de 1939, traballaron nela moitos exiliados e publicou numerosos libros aos republicanos, incluídos bastantes dos que pertencían á "Casa de España"; por tanto, mantiña ligazóns comerciais con Alfonso Reyes. 
Maruja adiántalle ao escritor que se estaban a fraguar as tres grandes editoriais da Arxentina. Era o momento, as vendas empezaban a recuperarse despois de que a crise de 1929 ocasionase a ruína da Compañía Iberoamericana de Publicaciones (CIAP) e a Guerra Civil o afundimento das editoras españolas, de que no grande país do Río de La Plata a reforma da educación e o crecemento da economía fixesen agromar compradores e porque se vía próximo o comezo da II Guerra Mundial. Por outra parte, Espasa-Calpe permanecía anquilosada nos clásicos e atenazada por que os donos impoñían publicacións de corte filofranquista. Dúas desas novas editoras emerxeron da man de republicanos que a pintora e o escritor coñecían, igual que a moitos dos intelectuais que se foron a traballar nelas ou se responsabilizaron de coleccións e cuxos nomes por diversos motivos figuran nas súas cartas.

EMECE púxoa en marcha Mariano Medina con capital judeo-chileno e o saber dos galegos Luís Seoane, Arturo Cuadrado e Álvaro de las Casas. Editorial Losada nace grazas a outro galego antes xerente de Espasa-Calpe, que para sacala adiante se apoiara no seu coñecemento do mercado e da distribución no cono sur e nun equipo no que primaban profesores universitarios e críticos de importantes revistas e dos suplementos dos grandes xornais. En Suramericana o seu director era catalán pero nela predominaba o diñeiro de magnates arxentinos, con González Garaño, E. Bullrich, Ocampo e Girondo no seu primeiro consello editorial; os dous últimos abandonárono ao optar Suramericana por un vieiro empresarial que asociaba calidade e ganancias: para ambos os rendementos eran totalmente secundarios.

O autor de Visión de Anahuac pasa por alto os adiantos de Maruja sobre esas editoriais das que posuía ampla información por Henríquez Ureña, Guillermo de Torre e Girondo. De Torre, xa o 13/5/1938, preveuno das escasas posibilidades de que Espasa-Calpe lle publicase Capitulos de Literatura Española e anticípalle o advenimento de Losada -nela chegará a ser o director literario-e a súa forma de pago, ademais de lle pedir obras para editar. Noutra carta do 6/8/1938, notifícalle a saída de H. Ureña, Romero e Amado Alonso de Sur e Espasa-Calpe, e o xeito de que esta empresa non saque a súa versión do Poema del Cid (García 2005: 158 e 161).
Reyes, de novo, é cauteloso ao non revelar a Maruja que a visita a Bos Aires de Cosío Villegas en 1941 obedeceu a tanteos para espallar o Fondo de Cultura Económica, un obxetivo que se materializou en 1945 ao abrir alí unha delegación con Orfilia Reynal ao frente. Continúa a ser cauto no relativo á expulsión dos redactores de Romance (antes de Hora de España), pois oculta que foi pola súa vinculación ao PCE que esguellaban bastante os contidos referidos a México e os desacordos co seu propietario, o exiliado Jiménez Siles (Pérez Rodríguez 2005: 54-60). Reyes coñecería ben as razóns do despido pola súa posición central no sistema cultural azteca, por pertencer ao consello editorial da revista, por Domenchina e porque para a adxudicación das subvencións que EDIAPSA recibía do gobierno foi decisivo que nela participase Martín Guzmán, compañeiro seu no "Ateneo de la Juventud de México" e con quen desenvolveu unha azarosa relación.

Arxentina admitiu a uns 2600 refuxiados fronte aos máis de 22.500 que aceptou México. De aí que Maruja queira coñecer quen estaba alí; curiosamente, os que Reyes lle detalla todos eran compoñentes da "Casa de España", unha institución constituída en agosto de 1938, con el de presidente ata a súa morte e Cosío de secretario. María Zambrano estivo ligada a ese organismo estatal que a destinou á universidade $\mathrm{S}$. Nicolás de Hidalgo, onde atopou carencias para a docencia de filosofía, certo baleiro por ser muller e un ambiente rareado pola resistencia ás innovacións educativas de Cárdenas; recordemos que nas universidades de Morelia, Guadalajara e no "Colegio Rosales" de Sinaloa, foi onde o goberno puxo especial empeño en implantar as reformas, mudanzas ás que non era allea a fundación e o programa da "Casa de España".

Nunha das cartas a Maruja, Reyes arrisca que no desgusto que sentiu Zambrano, tamén influiu residir nunha cidade pequena como Morelia, lonxe dos seus compañeiros de infortunio. A través do epistolario, verifícase como Maruja Mallo avoga pola filósofa ante el e como este capta o cariño que lle profesa, pois ata a avisa de que lle xiraron a París os dólares para a súa ida a México. Así mesmo, o 15/4/1939, Zambrano fai partícipe a Reyes do seguinte: "Tuve carta de mi familia en la que me dicen que después de mi salida de París, llegaran dos cartas 
de Maruja Mallo muy animosas y llenas de cariño, ofreciéndome no se cuantas cosas. Dicen que hablaba de usted"; e o 27/5/1939 dille que recibiu da pintora "una larga e encantadora carta" (Enríquez Perea 2006: 175). As misivas de Maruja revelan afecto cara á pensadora, pero, a xulgar polas peticións ao ensaísta para que lle lembre que lle escriba, xa en 1939, obtén escasa reciprocidade de María Zambrano.

A carta de Maruja a Alfonso Reyes do 16/7/1941 corrobora a existencia dunha barreira entre os exiliados, axentes sociosemióticos dentro do bando republicano, e as clases pudentes porteñas próximas ao eido da cultura; algo que lles aconteceu a case todos os refuxiados cos cidadáns arxentinos en xeral, xa que os valoraban como competidores, cando non como revolucionarios. En México confluían na repulsa dos asilados da Guerra Civil de 1936, o grande peso da hitleriana colonia centroeuropea coa oposición interna ao goberno que perseguía implantar os postulados da revolución de 1911 e protexía os desterrados.

Reyes, como lle di a Maruja, aproveitou as súas colaboracións na prensa no só para defendelos; así, en "Mis Gachupines" (El Universal $15 / 11 / 1939$ ) esgrime que era inxusto o descrédito xeneralizado dos españois e asevera que contribuíran ao desenvolvemento de México. Precisamente, no El Universal do 6/4/1939 inseriu unha das editoriais máis virulentas contra os refuxiados; era un dos medios contrarios a eles, xunto La Prensa, Foro Veracruzano ou revistas de grande circulación como Revista Hoy. Os xornais Excelsior e Novedades eran algo menos agresivos. A favor só El Popular, da Confederación de Trabajadores Mexicanos, sindicato presidido por Lombardero Toledado, de quen dependía a Universidade Obreira. Esta entidade editaba Revista de Cultura Moderna, onde a pintora publicou un artigo en 1936, e tamén $\mathrm{Fu}$ turo (que lle fixo a Reyes unha laudatoria benvida cando retornou a México), e probablemente será para unha destas revistas para a que ela, de acordo co que lle di ao escritor, remite en 1938 un artigo sobre Galiza.

A prepotencia nazi en México tivo unha das súas demostracións na violenta agresión (decembro de 1941) a Pablo Neruda en Cuernavaca, un duro ataque físico do que non sabemos se a artista tivo coñecemento. Igualmente descoñecemos se soubo dos serios problemas do poeta co seu gobierno entre maio e xullo de 1941, por conceder a Siqueiros un visado de entrada a Chile, despois do asasinato de Trotsky, e baixo o pretexto de ir pintar un mural á escola de Chillán, a vila máis danada polo destrutor tremor de terra de 1939. Ambas as dúas eran cuestións que a Maruja lle interesarían, polas consecuencias para a saúde e para a carreira profesional do recente cónsul, e que ben merecían de Reyes unha carta a primeira, e a última, como mínimo, referirse a ela nalgunha outra. Mais si se contaron a ilegalización da falanxe en México ou que a comunidade xermana en Arxentina realizara un referendo sobre a anexión de Austria (obtivo o $85 \%$ dos votos a favor) que carrexou unha conflagración entre anti e pro nazis cun saldo de dous mortos.

Segundo Ma Rosa Oliver (1981: 27), Maruja o primeiro que fixo "...no bien ganó lo suficiente ilustrando libros infantiles, fue irse a vivir a un apartamento nuevo". A correspondencia con Reyes certifica esta dedicación, que esporadicamente xa se dera en Madrid para libros dos seus amigos, algún de contos, como a tradución de Rafael Sánchez Mazas do segundo volume dos Cuentos de Basile. Quizais un dos seus principais clientes fose o grupo Atlántida, que tiña a Col. Biblioteca Infantil Atlántida e para adolescentes a Col. Biblioteca Billiken (dirixida por Rafael Dieste, igual que a Oro). Probablemente ela silenciou a súa faceta de ilustradora polo mesmo que a de decoradora de exclusivas vivendas de luxo e diseñadora de mobles ou teas: considerar que non acadaba igual rango que a de pintora.

A viaxe de Maruja Mallo a Chile en 1939, respondeu a un convite da Alianza Intelectual (fundada por Neruda e González Tuñón) para pronunciar conferencias. A do 25/1/1939 coincidiu co devastador sismo de $8^{\prime} 3^{\circ}$ e pospúxose nove días, o cal non mermou a masiva asistencia ao teatro Municipal de Santiago para escoitala departir sobre as atrocidades cometidas polos falanxistas, e non sobre o libro, como estaba previsto que disertaría na de xaneiro. A súa recadación repartiuse entre a "Asociación de $\mathrm{Mu}$ jeres a Favor de los Niños Españoles" e os damnificados polo tremor. Logo prolongou a súa estadía para ir á casa de Neruda, ás praias do Pacífico, a Valparaíso e a Viña del Mar. Voltou 
máis veces e sempre se hospedou nos mellores hoteis, consciente de que iso lle facilitaría a venda dos cadros que normalmente levaba consigo. Subliñamos que en 1945, nin a Reyes ni a Concha Méndez lles conta que fose á illa de Pascua co premio Nobel, o cal axuda a avalar a hipótese de que non fixeran esa visita a Rapa Nui. Porén, en senllas cartas do 25 de agosto, relátalles o mesmo e con case igual vocabulario do seu desaparecido mural "Armonías Plásticas" no cine "Los Angeles". A Concha Méndez dille:

Este año pasé el verano en la costa del Pacífico de Chile, que es extraordinaria, como el viaje aéreo sobre los Andes, sobre todo el Aconcagua. Fui este año allí a tomar documentales en la costa para tres muros, $6.75 \times 4$ cada uno, para un edificio público de Bos Aires que acaba de realizarse el mes pasado. Este edifico es un monumento arquitectónico en las dos más céntricas calles de aquí. Es de vidrio su fachada, así que queda como una exposición permanente e internacional. (Ferris 2004: 267)

Entre 1941 e 1945 Maruja gozou dun período álxido por recibir da Casa Comte (1943) encargos para deseñar textiles e mobles e por seguir a codearse co mellor dos grandes potentados bonaerenses. Era asidua aos seus "saraos" e reunións (Oliver 1981: 28-29); eventos, aventuramos, que para ela non estarían exentos de sentido comercial. Nos seus moi demorados veraneos en Punta del Este coincidía coa oligarquía uruguaia, con algunha brasileira e con moita da Arxentina (despois con xerarcas e empresarios peronistas); albergábase nos complexos hosteleiros máis luxosos, participaba intensamente na vida social e procuraba vender a súa obra, tal como se desprende do que lle escribe a Reyes. A ese balneario acudían amigos personais dos dous, como as Correa, a quen o ensaísta cita bastante no diario de 1937, ou as irmás Bombal.

Con $\mathrm{M}^{\mathrm{a}}$ Luisa Bombal, novelista adiantada ao "realismo máxico", nunha das misivas utiliza un duro sarcasmo puntualizador cando apostila por que disparou contra o millonario Sánchez Errázuriz, un dos pioneros da aviación en Chile e alí xefe dunha dereitista organización paramilitar con máis de 7000 afiliados. Era moi amiga de Neruda (mesmo partillaran a táboa de escribir) e, polo ton da carta, Maruja, debeu ter cumprida relación con ela. Pero namentres a produción da nosa artista non reflicte o sometemento da muller nin a loita por ocupar unha posición de paridade con respecto ao home, en Última Niebla (1935) e en La Amortajada (1938), o halo onírico no que Bombal envolve a trama non enmascara a crenza da autora de que a muller e a natureza están subordinadas ao interesado dominio masculino.

Outra das razóns para que Maruja se apartase dos refuxiados talvez radique en que os AlbertiLeón señoreasen un dos centros político-culturais máis potentes e activos de Bos Aires. Perto, ou "alistados" a el, había arxentinos con forte presenza na literatura, no teatro e na plástica; entre eles, o matrimonio Rojas Paz - Sara Tornú do que lle fala a Reyes con antipatía. Neruda e Lorca coñecéronse na súa casa e compuxeron para "La Rubia" intelectual e materialmente o único exemplar de Paloma por dentro y por fuera o sea la mano de vidrio, un álbum no cal os sete desolados poemas do chileno ilústraos o granadino con debuxos que lembran os da súa etapa en Nova York.

Entre as amizades da artista destacaban os homes (Mangini 2012: 23), e Sara Tornú non reunía un perfil acaído para lle agradar: era culta, atractiva, moderna, amiga de Neruda, de Sábato, Lorenzo Varela, Berni, Seoane, Losada, Baudizzione, Forner, Leónidas Barletta..., e "presidía" unha tertulia. Nas súas memorias, $\mathrm{M}^{\mathrm{a}}$ Rosa Oliver (1981: 28-29), describe con inclemencia a M. Mallo, pero tampouco lle gustaba "La Rubia" (nin nesas datas Alberti ou Neruda) a resultas do que lle comenta a Reyes o 27/7/1947 dun acto do que non di se asistiu Maruja:

Aquí tenemos a Cándido Portinari, León Felipe, Nicolás Guillén y Pablo Neruda. Con el primero mudo en el escenario y agregado a Rafael Alberti dieron ayer un recital de poesía a beneficio de la España resistente. El inmenso local de las Federaciones Gallegas se llenó a reventar (...) Cambia todo, lo único inmutable es la Rubia Rojas Paz, siempre igual, siempre en primera fila y en evidencia. Es la perfecta Evita Duarte de los intelectuales; tiene menos joyas, menos poder, la pobrecita, pero igual tendencia al descamisamiento moral. (Zaïtzeff 2009: 131)

$\mathrm{Na}$ órbita de Alberti-León, de certo, aliñábanse Pablo Rojas Paz, o premio nacional de novela (que, como comentarista deportivo de Crítica, asinaba as súas metafóricas crónicas baixo o pseudónimo de "El negro de la tribuna"), a 
activista e pintora Margot Parker e Raúl González Tuñón. Este último foi representante de Arxentina no II Congreso Internacional de Escritores de Valencia e autor de La Rosa Blinda$d a$ (1936), un poemario inspirado na revolución de Asturias de 1934, que, para moitos investigadores, influíu en Viento del Pueblo, de Miguel Hernández. Tuñón procurou que en 1936 se estrease en Bos Aires Los hios de la piedra, e, curiosamente, foi quen aloxou na súa casa a Maruja Mallo desde que esta chegara a Bos Aires ata mediados de maio de 1937. Nesa data a súa dona, Amparó Mon, veu para España, onde xa se atopaba el de corresponsal de guerra (Enríquez Perea 2012: 107); daquela, a pintora foise vivir na embaixada azteca. Engadimos que era moi amigo de Margarita Nelken, e que a pregunta de Maruja a Reyes sobre a congresista (non 1la responde), non debe deslindarse da oposición desta nas Cortes de 1931 ao voto feminino, da súa militancia no PCE, nin de certo roxelo pola crítica adversa que lle fixo antes da Guerra Civil (Nelken 1936).

Nin Reyes nin Mallo reflexionan no seu epistolario en torno á súa obra. Unicamente ela, ao describir o seu departamento da elegante rúa Santa Fé, revela a súa querenza polos obxectos da natureza e pola decoración pouco común. Entre 1937 e 1945 a produción de Reyes experimenta a suxestión da cultura mexicana e a pegada do pensamento americanista; e foi considerábel e do calibre de Capitulos de literatura española, La antigua retórica, La expresión literaria, Última Tule, El deslinde ou Crítica de la Edad Ateniense. A de Maruja foi curta, se ben pertencen a eses anos as súas tres series máis representativas. As tres están confeccionadas con meticulosidade e pulcritude, fan gala da racionalidade e depuración sobre o discurso que acredita a intelectualización que singulariza a plástica da artista.

"A relixión do traballo", que arrinca de $A$ Sorpresa do trigo (1936), rende tributo aos mariñeiros e ás labregas, sen contravir os roles que tradicionalmente desempeñaran macho e femia. Nesta serie transmuta a muller nun ídolo propiciador dos froitos do mar e da terra, nun ser máxico e protector que plasma sen a converter nun símbolo e sen infrinxir o papel que lle asigna o modelo de xénero que impón a fertilidade como un dos preceptos fundamentais. Porén, esa deificación está indefectibelmente unida ao recoñecemento do traballo feminino no cultivo agrícola.

En "A relixión do traballo" pervive a súa técnica elaborada e puída, a composición construtivista e as formas xeométricas; persiste unha concepción muralista e, ao igual que nas outras dúas series, a pintora pensa nun receptor ideal posuidor das claves para principiar un diálogo co que ve. Todos os estudosos conectan a organización destas obras co estruturalismo e a iconografía e cromatismo con imaxes pretéritas dos campos de Castela, unhas imaxes que cremos avivadas polas inmensas extensións de trigo en Arxentina. As de discurso marítimo pintadas antes de 1939 engrénanas aos bosquexos que executou en Galicia en xullo de 1936, sen ponderar que desde que se instalou en Bos Aires para ela rebordaron o denotativo e se converteron nun asideiro emocional, que a súa reinterpretación responde á necesidade de rescatar as semanas de felicidade na ría de Vigo. Por outra banda, despois de ler as súas misivas a Reyes, a cor dos cadros referidos ao universo marino cómpre asociala á paisaxe gris azulada do río de La Plata e á luz rutilante que penetraba polos ventanais da súa casa. Esta serie compóñena en boa medida as obras que a rodean nas fotos que lle remitiu ao escritor; entre eles "O canto das espigas" (1939-1941).

Tras a viaxe a Chile de 1939, comeza "Naturezas Vivas" fascinada pola costa do Pacífico e os elementos mariños dos seus areais. É unha serie con algún cadros que trasladan ao espectador certo desacougo e sensación de tormento, e que ao ollala fai pensar se a decepción da pintora coa "raza humana" agora a permutara pola comuñón co ecosistema virxe; se reemprazara o ideoloxema de corte social que subxace en "A relixión do traballo" por unha figuración cargada de simbolismo erótico-telúrico ou erótico-vexetal. É unha serie conformada en base a imaxes sensuais e metarrealistas; porén, a técnica continúa a ser preciosista. Esa factura, que despois de 1938 adquire categoría de estilema, segue en "Retratos bidimensionais", unhas escultóricas cabezas que realiza ao longo da década e que asimilamos á plasmación de arquetipos do semblante externo do seu ansiado novo ser humano: unha simbiose de muller-home, crisol de etnias. Parece que neses "retratos" modelase 
a esa soñada criatura prístina e límpida que substituiría á actual, na cal tanto o ensaísta como ela en 1939 aseguraban ter perdido a fe.

O estudo das cartas entre Maruja Mallo e Alfonso Reyes constitúen unha fonte de información primaria para afondar en como se desenvolveron os primeiros anos da artista en Bos Aires. Por el coñecemos onde xurdiu e cal foi a rede que lle prestou apoio á súa chegada, a súa rápida acomodación a un modo de vida moi diferente ao que tiña en Madrid, que residiu na casa de González Tuñón, amigo de Miguel Hernández, nas embaixadas de México e España, e que desde moi cedo estaba ao tanto do nacemento das grandes editoras porteñas. Permítenos coñecer como lle afectaron a guerra civil e a europea, como a amizade con Reyes a achegou á masa de refuxiados ao propiciarlle este que fixese a escenografía para a Cantata en la Tumba de Federico Garcia Lorca, unha peza teatral que se representou por terceira vez ante miles de republicanos.

Grazas á análise cognoscitiva deste epistolario, confirmamos o moito que estaba integrada no grupo editorial Atlántida, que ilustrara libros infantís e que iso lle permitira subsistir nos primeiros tempos; que a decoración nada convencional do seu piso atraía pola súa novidade e orixinalidade os seus exclusivistas "amigos", o cal nos revela o xermolo doutra das facetas á que, moi selectivamente, se dedicará a partir de 1946. Doutra parte, verificamos que detrás da súa vida mundana existía o lado comercial da venda dos seus cadros, así como a atracción que exerceron sobre ela o litoral do Pacífico e os Andes.
O estudo das cartas tendo en conta o contexto sociopolítico da época e dos lugares onde as escribiron tamén nos achega á complexa recepción que tiveron os exiliados de 1936-1939 en Arxentina e México; ratifica que no trienio inicial do seu exilio a nosa artista se involucrou na loita contra o franquismo e que, ao tempo disto, pinta "A relixión do traballo", unha serie que retivo o ideoloxema de "A Sorpresa do Trigo". Así mesmo, descúbrenos que permaneceu ao lado de Constancio Vigil ata o seu pasamento, e un sentido da amizade e unha dimensión afectiva que non saíron á luz por quedaren afogados por outros factores seus máis iconoclastas, ou polo seu modo de actuar nos anos posteriores a 1945.

A análise da correspondencia cruzada entre Reyes e Maruja Mallo desvela en maior medida a biografía persoal e creativa da pintora que do escritor; permítenos constatar a complicidade existente entre eles e o talante de ambos ante certos feitos ou comportamentos, aínda que ningún dos dous exterioriza confidencias íntimas ou criterios sobre os acontecementos da época. El é bastante hermético; incluso, cando ela llo demanda, non opina sobre os seus cadros ou os seus textos, nin siquera cando lle pregunta a súa opinión acerca do título "Lo popular en la plástica española a través de mi obra", pese a evocar este o de "Lo popular en Góngora", un artigo de Reyes igualmente de 1938. E, sen dúbida, o estudo das cartas entre Alfonso Reyes e Maruja Mallo contribúe a rachar a máscara defensiva que eles mesmos se construíron.

\section{REFERENCIAS BIBLIOGRÁFICAS}

Alonso Montero, Xesús (1998): Os poetas con Federico García Lorca e coa España republicana. (Bos Aires, 1937). Introdución á edición facsímile de Homenaje de escritores e artistas a García Lorca-Mony Hermelo, recital poético (Bos Aires / Montevideo 1937). Santiago de Compostela: Universidade.

Bockus Aponte, Bárbara (1972): Alfonso Reyes an Spain. Hid Dialogue with Unamuno, ValleInclán, Ortega y Gasset, Jiménez and Gómez de la Serna. Austin: University of Texas Press.

Curiel, Fernando (ed.) (1991): Reyes - Guzmán. Correspondencia 1913-1959. México: UNAM.

Enríquez Perea, Alberto (comp.) (1999): Testimonios de una amistad. Correspondencia. Alfonso Reyes - Daniel Cosío Villegas. México: FCE, El Colegio de México.

(2006): Dias de Exilio. Correspondencia entre $M^{a}$ Zambrano y Alfonso Reyes. 1939-1959. México: Ed. Taurus, El Colegio de México. 
(2012): Alfonso Reyes. Diario. Tomo IV. México: FCE, El Colegio de México.

Ferris, José Luis (2004): Maruja Mallo. La gran transgresora del 27. Madrid: Ed. Temas de Hoy.

Frontini, Norberto A. (comp.) (1937): Homenaje a Federico García Lorca de escritores y artistas. Buenos Aires: Talleres Gráficos Porter Hnos.

García, Carlos (ed.) (2005): Alfonso Reyes/Guillermo de Torre. Las letras y la amistad. Valencia: Ed. Pre-Textos.

LARA, Juan Jacobo de (comp.) (1981): Henríquez Ureña y Alfonso Reyes. Epistolario Íntimo 19061946. Santo Domingo: Ed. Universidad Nacional.

LidA, Clara (1998): La Casa de España en México. México: El Colegio de México.

Horan, Elizabeth / Doris Meyer (comp. e prol.) (2007): Mistral, Gabriela y Ocampo, Victoria. Esta América Nuestra. Correspondencia 1926-1956. Buenos Aires: Ed. Cuenco de Plata.

Huici, Fernando (1978): “Entrevista con Maruja Mallo”, Camp de l'Arpa 53, pp. 27-31.

Mallo, Maruja (1936): "La Plástica". U.O. Revista de Cultura Moderna (agosto-septiembre), s. p. (1938): "Relato veraz de la realidad de Galicia", La Vanguardia 14, 16 e 21/9/1938.

Mangini, Shirley (2012): Maruja Mallo. Barcelona: Circe Ediciones.

Molins, Patricia (2012): "La heterogenidad como estrategia de afirmación”, Desacuerdos 7, pp. 64-139.

Montoya de Burundarena, Elena (1963): El teatro y sus enemigos. Buenos Aires: Ed. Ver.

NASH, Mary (1999): Rojas: Las mujeres republicanas en la guerra civil. Madrid: Ed. Taurus.

Nelken, Margarita (1936): "Exposición Maruja Mallo", Claridad 11, s. p.

Oliver, Ma Rosa (1981): Mi Fe es el Hombre. Buenos Aires: Ed. Carlos Lohlé.

Perea, Héctor (ed.) (1983): Alfonso Reyes/Victoria Ocampo. Cartas hechadas. Correspondencia 1927-1959. México: Ed. Universidad Autónoma Metropolitana.

Pérez Rodríguez, Ma Antonia (ed.) (2005): Lorenzo Varela en Revistas Culturales de México e Bos Aires. Taller, Romance, Letras de México, De Mar a Mar, Correo Literario, Cabalgata, Sur. Santiago de Compostela: Consello da Cultura Galega.

Quezada, Abraham (ed.) (2004): Pablo Neruda. Epistolario viajero 1927-1973. Santiago de Chile: Ed. RIL.

Reyes, Alfonso (1938): “Lo popular en Góngora”, Ruta. Revista Mensual de Literatura 1.

Robledo Rincón, Eduardo (coord.) (1998): Alfonso Reyes en Argentina. Buenos Aires: EUDEBA.

Rodrigo, Antonina (1988): Margarita Xirgu. Madrid: Ed. Aguilar.

Ruedas de la Serna, Jorge (ed.) (2011): Alfonso Reyes. Diario III 1930-1936. México: FCE.

Seoane, Luís (coord.) (1938): La Galice sous la botte de Franco. Paris: Ed. J. Flory.

Ulacia Altolaguirre, Paloma (1990): Concha Méndez. Memorias habladas, memorias armadas. Madrid: Ed. Mondadori.

Vargas SaAvedra, Luis (ed.) (1991): Tan de Usted. Epistolario de Gabriela Mistral con Alfonso Reyes. Santiago de Chile: Ed. Hachette, Universidad Católica.

ZAïtтZEF, Serge Ivan (comp.) (2008): 20 epistolarios rioplatenses de Alfonso Reyes. México: El Colegio Nacional.

(comp.) (2009): Más epistolarios rioplatenses de Alfonso Reyes. México: UAM.

Zuleta Miranda, Ma Cecilia (1996): “Alfonso Reyes y las relaciones México-Arxentina: proyectos y realidades, 1926-1936". Revista de Historia Mexicana 45/4, pp. 867-905. 